\title{
The Influence of Anaesthetic Choice on Electroconvulsive Therapy Parameters; Etomidate Versus Methohexital
}

\section{Laila Chomrikh'}

Erasmus University Medical Centre

Mustafa Ahmadi

Erasmus University Medical Centre

Martijn Kuijper

Maasstad Academy, Maasstad Hospital

Joris J.B. Van der Vlugt

Antes

Seppe J.H.A. Koopman ( $\sim$ koopmanj@maasstadziekenhuis.nl )

Maasstad Hospital

\section{Research Article}

Keywords: electroconvulsive therapy, affective disorder, etomidate, methohexital, seizure duration

Posted Date: December 28th, 2021

DOI: https://doi.org/10.21203/rs.3.rs-1192779/v1

License: (9) This work is licensed under a Creative Commons Attribution 4.0 International License. Read Full License 


\section{Abstract \\ Background}

Many of the anaesthetic drugs used for electroconvulsive therapy have anticonvulsant properties and may influence efficacy of electroconvulsive therapy. With this study we aim to provide more information on the effect of etomidate and methohexital on seizure duration. We explore the relationship between induction drug, motor and electroencephalography seizure duration. Moreover, we study the relationship of seizure duration and number of therapies.

\section{Methods}

In this retrospective study we collected data from patient records from 2005 until 2016. Inclusion criteria were the use of etomidate and/or methohexital and documentation of dosage, electroconvulsive therapy dosage and seizure duration. Exclusion criteria were missing data on either induction drug, dosage or seizure duration.

\section{Results}

Thirty seven patients were analysed. The mean age was 52 years and seventy six percent were female. Most patients were suffering from affective disorders (81\%). Motor and electroencephalography seizure duration were analysed in 679 and 551 electroconvulsive therapies, respectively. Compared to methohexital, motor and electroencephalography seizures under etomidate were 7 and 13 seconds longer, respectively. Furthermore, there was a negative association between seizure duration and number of treatment and a negative association between seizure duration and electroconvulsive therapy dosage.

\section{Conclusions}

This study demonstrates significant longer motor and electroencephalography seizure duration using etomidate compared to methohexital. Etomidate might therefore increase the effectiveness of electroconvulsive therapy. Moreover, we observed a negative association between seizure duration, number of treatment and electroconvulsive therapy dosage. With this study we contribute to the available literature comparing methohexital and etomidate as induction agents for electroconvulsive therapy.

\section{Introduction}

Electroconvulsive therapy (ECT) is a safe and effective treatment of severe and medication resistant psychiatric disorders such as depression and mania ${ }^{1}$. An electrical current is applied to the brain via transcutaneous electrodes while the patient is under general anaesthesia. This electrical current results in 
a generalized (motor) seizure accompanied by an acute cardiovascular response due to activation of the autonomic nervous system.

Despite uncertainties in the literature regarding good indicators for the efficacy of ECT, there is evidence that there is a relationship between the seizure duration and the effectiveness of ECT ${ }^{2-5}$. Many of the anaesthetic drugs used for ECT have anticonvulsant properties and may alter seizure parameters, e.g. the decrease of the duration of the induced seizure activity. They might therefore decrease the effectiveness of ECT.

Methohexital, a short-acting barbiturate, remains the most widely used anaesthetic for ECT due to its potential for long seizure duration and is recommended as drug of first choice for ECT by the American Psychiatry Association ${ }^{6-8}$. Despite this fact, etomidate gained popularity as an anaesthetic agent for $E C T$, due to its positive effects on electroencephalography (EEG) and motor seizure duration. Furthermore, it has a fast onset of action, short duration of effect and offers haemodynamic stability ${ }^{8,9}$. The use of etomidate is associated with longer EEG and motor seizure durations. This might be because the absence of anticonvulsant effect of etomidate. Thus, it could be the induction drug of choice in patients experiencing inadequate seizure activity $6,7,10,11$. Furthermore, it is described as the only induction agent that may reduce ECT dosage ${ }^{6}$.

There are a limited number of studies comparing methohexital and etomidate in the use for ECT and these data are inconsistent ${ }^{10,12-15}$. Some studies show no difference between etomidate and methohexital. Others show longer seizure duration and reduction of ECT dosage in favour of etomidate. Nonetheless, superiority or inferiority over methohexital could not be demonstrated with the presently available literature ${ }^{8,10,12-14}$.

\section{Study aim}

In our hospital either methohexital or etomidate is used in patients undergoing an ECT. The choice of induction drug depends on the preference of the anaesthesiologist. In the same patient, etomidate and methohexital might both have been used. This minimizes potential confounders and facilitates a 'crossover' design.

With the present study we aim to provide more information on the effectiveness of etomidate compared to methohexital on ECT parameters. We will explore the relationship between induction drug and seizure duration measured by both motor seizure activity and EEG. Moreover, we will study the relationship of seizure duration and number of treatments.

\section{Material And Methods}

\section{Study design}


The present study is a retrospective analysis of electroconvulsive therapy performed in our clinical institution from 2005 until 2016. The study was approved by the medical ethical committee (Toetsingscommissie Wetenschappelijk Onderzoek Rotterdam en omstreken; TWOR, 2016-61) and the need for written informed consent was waived. This study was performed in accordance with the Declaration of Helsinki. Hemodynamic data, induction drug and dosage, duration of seizure (both motor and EEG seizures) and demographic data were all recorded in patient records.

We included patients receiving electroconvulsive therapy between 2005 and 2016. Patients were included if they received etomidate and/or methohexital and if dosage, ECT dosage and duration of seizure were recorded. Patients with missing data on either induction drug, dosage or seizure duration were excluded.

\section{Outcome}

We explored the relationship between induction drug and seizure duration measured by both motor and EEG seizure activity. Motor seizure duration was defined as time from electrical stimulation to resolution of clonic activity in an isolated limb. EEG seizure duration was the time from delivery of electrical stimulus to postictal EEG suppression.

Furthermore, we studied the relationship between seizure duration and induction drug dosage and number of past treatments.

\section{Data collection}

Data was collected from the hospital records (both paper and electronic). Baseline data included age, sex, number of ECT sessions, psychiatric diagnoses and diagnosis of kidney failure, cerebrovascular accident or epilepsy. In addition, we collected the subsequent data per ECT session; anesthetic agent and dosage used per therapy, opioid use, antihypertensive drug use, benzodiazepine use, antipsychotic drug use, tricyclic antidepressant use, uni- or bilateral stimulation, impedance, pulse width of the electrical stimulus, frequency used, ECT dosage, motor and EEG seizure duration and hemodynamics (systolic and diastolic pressure, heart rate). Because of differences in schedule time of the ECT between different days, we also documented the day at which the ECT took place. We performed a stratified analysis of these data.

The data was handled in accordance with the Dutch Data Protection Act and the privacy regulation of the Maasstad Hospital. Each patient was allocated an unique identification number. Data was directly entered into a secured online database management system. Permission for this study was granted by the Institutional Review Board.

\section{Statistical analysis}

Descriptive statistics

Descriptive statistics were presented as counts and percentages (dichotomous variables) or means and standard deviations (normally distributed continuous variables). Non-normally distributed, continuous variables will be described as medians with interquartile range. Continuous data were compared using 
the paired t-test. Categorical data were compared using the McNemar's test. Effects were described with their $95 \%$ confidence intervals $(95 \% \mathrm{Cl})$.

Relationship between induction drug and seizure duration.

The relationship between seizure duration and induction agent was modeled by repeated measures analysis using a linear mixed model with random intercept for patient and random slopes for treatment number and induction drug. Measurements up to 365 days after start of convulsion therapy were included. To allow for easier interpretation of parameters, covariate ECT dosage was centered at $100 \%$, while covariates drug dosage for etomidate and methohexital were centered at their most frequently prescribed dosages of $20 \mathrm{mg}$ and $100 \mathrm{mg}$ respectively. Covariates include a dummy variable for induction drug (etomidate, reference methohexital), number of treatment, ECT dosage (range $0-200 \%$, centred at 100\%) and induction drug dosage, centred at $20 \mathrm{mg}$ (etomidate) and $100 \mathrm{mg}$ (methohexital). For both outcomes (motor seizure activity and seizure activity on EEG), the following model building strategy was undertaken. First, relationships between outcome and covariates time, ECT dosage, induction drug and dosage were graphically assessed by scatter plots. Secondly, saturated models were fit for each drug separately, including all interactions for time, dose and induction threshold. Starting with the three-way interaction, interaction terms were sequentially removed in case the likelihood ratio-test Chi2-statistic was not significant for that term (which proved to be the case for all the interaction terms). Thirdly, models for both drugs were combined, starting with all two-way interactions between induction drug and covariates time, ECT dosage and dosage (the drug-dosage interaction term being forced into the model for interpretation). Again, interactions terms were sequentially removed based on the likelihood ratio-test Chi2-statistic. All models were fit with a random intercept for patient and random slopes for treatment occasion and an unstructured covariance for the random effects under full maximum likelihood. For the final models, the addition of a random slope for induction drug and allowing for heterogeneity in residual errors by drug were tested by the likelihood test under restricted maximum likelihood. These resulted in a small but significant improvement in model fit and were hence incorporated in the final models.

P-values $<0.05$ were considered statistically significant.

\section{Results}

\section{Demographics}

From 2005 until 2016, 102 patients were treated with ECT. Yet, we only found complete hospital documentation of 37 patients (see figure 1).

A number of 37 patients were analysed. The mean age of the patients was 52.3 years (median 50, sd 13.7, interquartile range (IQR) 44-63 (number $(N)=37$ ). Seventy six percent were female. Most patients were suffering from affective disorders (81\%) and three patients (8\%) were diagnosed with schizophrenia. Psychiatric diagnosis was unclear in four patients (11\%). See Table 1 for the demographic data. 
Medication use and comorbidity are described in Table 1. Benzodiazepines and antipsychotic drugs were the most frequently used drugs. We also documented the number of patients with missing information on their medication use.

Table 1

Demographic characteristics

\begin{tabular}{|lc|}
\hline Characteristic & Number \\
\hline Age, mean (sd) & $52.3 \mathrm{yr}$ \\
\hline Gender, $\mathrm{n}(\%)$ & $9(24)$ \\
Male & $28(76)$ \\
Female & \\
\hline Diagnosis, $\mathrm{n}(\%)$ & $30(81)$ \\
Affective disorder & $3(8)$ \\
Schizophrenia & $4(11)$ \\
Unclear & \\
\hline Comorbidity, $\mathrm{n}(\%)$ & $1(3)$ \\
CVA/TIA & $2(6)$ \\
Epilepsy & $4(13)$ \\
Renal impairment (GFR <60) & \\
\hline Medication use, $\mathrm{n}(\%)$ & $11(31)$ \\
Antihypertensive drugs & $23(70)$ \\
Antipsychotic drugs & $25(74)$ \\
BenzodiazepineTricyclic antidepressantOpioids & $10(29)$ \\
& $0(0)$ \\
\hline
\end{tabular}

yr year; sd standard deviation; n number; ECT electroconvulsive therapy; EEG electroencephalography; CVA cerebrovascular accident; TIA transient ischemic attack; GFR glomerular filtration rate; Std. error: standard error; Cl: 95\% confidence interval

\section{ECT parameters}

A total number of 679 and 551 ECT were included for analysis regarding motor seizure duration and EEG seizure duration respectively.

Patients received an average of 23 therapies in the first year following the first ECT. Methohexital was used in $49.5 \%$ of these treatments. Etomidate was used in $31.5 \%$ of the treatments. Propofol was used in 
three treatments $(0.3 \%)$. In $18.7 \%$ of the treatments, induction drug was not reported. These patients were not included in the analysis

\section{Induction drug and seizure duration}

Fixed effects coefficients for the final linear mixed model for seizure duration are shown in Table 2. A negative association of $-0.27(95 \% \mathrm{Cl}-0.51-0.02)$ seconds for each subsequent treatment is observed between seizure duration and number of treatments. A negative association is observed between seizure duration and ECT dosage as well; -0.05 (95\% CI -0.08 - -0.01) seconds per percent increase in ECT dosage. Both induction agents show a negative dose-response relationship. For etomidate it is $-0.36(95 \% \mathrm{Cl}-0.64$ - -0.07) and for methohexital: $-0.13(95 \% \mathrm{Cl}-0.18-0.09)$ seconds per milligram increase in dosage of induction drug. Overall, for reference dosages of $20 \mathrm{mg}$ and $100 \mathrm{mg}$ for etomidate and methohexital respectively, seizures induced under etomidate had on average a longer duration compared to methohexital (6.69 (95\% Cl 1.43 - 11.95) seconds). Similar results were obtained for seizure duration on EEG. Seizures induced by etomidate were on average 13.40 (95\% Cl 8.38 - 18.42) seconds longer compared to methohexital at their respective reference dosages (Table 3).

Table 2

Relationship between motor seizure duration and induction drug

\begin{tabular}{|c|c|c|c|c|}
\hline Motor seizure duration & Regression coefficient & Std. error & $p$ & $95 \% \mathrm{Cl}$ \\
\hline Treatment number ${ }^{+}$ & -0.27 & 0.13 & 0.04 & $-0.15--0.02$ \\
\hline ECT dosage $\$$ & -0.05 & 0.02 & 0.01 & $-0.08--0.01$ \\
\hline Etomidate \# & 6.69 & 2.68 & 0.01 & $1.43-11.95$ \\
\hline Etomidate dose * & -0.36 & 0.15 & 0.01 & $-0.64--0.07$ \\
\hline Methohexital dose * & -0.13 & 0.02 & 0.00 & $-0.18--0.09$ \\
\hline \multicolumn{5}{|c|}{$\begin{array}{l}\text { +Seconds per each subsequent treatment; } \$ \text { Seconds per percent increase in ECT dosage; }{ }^{*} \text { Reference } \\
\text { dose: etomidate } 20 \text { mg, methohexital } 100 \text { mg; }{ }^{*} \text { (seconds / mg increase in dosage) }\end{array}$} \\
\hline \multicolumn{5}{|c|}{ Std. error: standard error; $95 \% \mathrm{Cl}$ : 95\% confidence interval } \\
\hline
\end{tabular}


Table 3

Relationship between EEG seizure duration and induction drug

\begin{tabular}{|c|c|c|c|c|}
\hline EEG seizure duration & Regression coefficient & Std. error & $p$ & $\mathrm{Cl}$ \\
\hline Treatment number ${ }^{+}$ & -0.27 & 0.15 & 0.08 & $-0.57-0.03$ \\
\hline ECT dosage $\$$ & -0.09 & 0.03 & 0.00 & $-0.15--0.04$ \\
\hline Etomidate $\#$ & 13.40 & 2.56 & 0.00 & $8.38-18.42$ \\
\hline Etomidate dose * & -0.58 & 0.21 & 0.01 & $-1.00--0.16$ \\
\hline Methohexital dose * & -0.12 & 0.03 & 0.00 & $-0.18--0.05$ \\
\hline \multicolumn{5}{|c|}{$\begin{array}{l}\text { +Seconds per each subsequent treatment; } \$ \text { Seconds per percent increase in ECT dosage; }{ }^{*} \text { Referenc } \\
\text { dose: etomidate } 20 \mathrm{mg} \text {, methohexital } 100 \mathrm{mg} ;{ }^{*} \text { (seconds / mg increase in dosage) }\end{array}$} \\
\hline
\end{tabular}

\section{Discussion}

In our study, we have shown that etomidate is associated with a long seizure duration (both EEG and motor) compared to methohexital. Furthermore, there is a negative dose-response relationship with the use of both induction agents. We also demonstrated a negative association between seizure duration and number of treatment and between seizure duration and ECT dosage.

Literature regarding the optimal induction drug for ECT is inconsistent. Our findings differ from a study by Eser et al ${ }^{12}$. They performed a retrospective analysis of 5482 ECTs in 455 patients treated between 1995 and 2003. There was no difference between induction with etomidate or methohexital in seizure duration 12, 13. The mean dosage of administered methohexital and etomidate was higher compared to our patient population (130 mg and $32 \mathrm{mg}$ compared to $100 \mathrm{mg}$ and $20 \mathrm{mg}$, respectively) ${ }^{16}$. And to achieve adequate seizures, patients with higher ECT dosage received methohexital more frequently than other induction drugs. In our patient group, the choice for using methohexital or etomidate was not based on ECT dosage but rather on the preference of the attending anaesthesiologist. Switches in induction drug in one patient were thus at random. The higher drug dosage and the use of methohexital in patients with higher ECT dosage could be an explanation for the different results.

A more recent systemic review and meta-analysis of Singh and colleagues ${ }^{8}$ included seventeen trials involving the use of etomidate, methohexital, thiopental and propofol as induction agents for ECT. Four trials compared etomidate with methohexital ${ }^{13-15,17 .}$

A total of 84 ECT settings were included in this meta-analysis. The etomidate group showed a longer EEG and motor seizure duration of etomidate compared to methohexital (2.23 and 1.45 seconds, respectively). This difference was, however, not statistically significant. Thus, the study was underpowered to 
demonstrate superiority of etomidate over methohexital. Another study in line with our finding is the research of Avramov's et al ${ }^{10,14,15}$. They studied a small group $(N=10)$ of patients with chronic depression with a total of 90 ECTs in a randomized cross-over study comparing etomidate and methohexital. Their results showed longer durations of EEG and motor seizures after etomidate with no clear dose-effect relationship.

Limitations of this study include the retrospective design and the limited number of patients $(\mathrm{N}=37)$. Though there were 102 patients treated from 2005 until 2016, we only found hospital documentation of 37 patients. The large number of missing patient records might affect the internal validity of our study. Comparing baseline characteristics of patients excluded because of missing data, no differences were found. This decreases the risk of non-randomly distributed missing data. We therefore think that our result are valid, both internally as externally. Despite the large amount of missing data, we were able to show a significant result, thus our study was not underpowered. Another limitation is the retrospective design and the large study period. During this study period, treatment remained largely the same. Any treatment effect found in this study is less likely due to chances in treatment but more likely due to a true difference in seizure duration between etomidate and methohexital. Regarding our outcome measures, we were unable to study effectiveness of ECT. We used seizure duration as a proxy. Although there are uncertainties in the literature regarding good indicators for the efficacy of ECT, seizure duration is universally accepted as marker for effectiveness of ECT ${ }^{2-5}$. Antiepileptic medication was not corrected for in the final model. Although mentioned in the guidelines as medication which affects the seizure duration, there is no reason to presume medication used differed between the two groups. ${ }^{11}$

The strength of this study was the fact that we were able to include a good number of patients who were anesthetized with both etomidate and methohexital. This made the patients their own control, thus elimination several confounders. Furthermore, the choice of induction drug was based on the preference of the attending anaesthesiologist. This made confounding by indication less likely. We used this in our analysis by using linear mixed model and at the same time we could correct for confounders as ECT dosage, induction drug dosage and sensitization effect (number of treatments). We believe that, due to lack of confounding by indication, non-random loss-to-follow-up and an advanced statistical model, our results are valid. Although a difference of 6,69 seconds in motor seizure duration and 13.4 seconds in EEG seizure duration might not seem clinically relevant, it's a decrease of $23 \%$ and $39 \%$ of the average motor and EEG seizure duration respectively.

In conclusion, this study demonstrated a longer EEG and motor seizure duration with the use of etomidate in comparison to methohexital. Moreover, we observed a negative association between seizure duration and number of treatments and a negative association between seizure duration and ECT dosage. With this study we contribute to the available literature comparing methohexital and etomidate as induction agents for ECT.

\section{Declarations}


Ethics approval and consent to participate

Ethical approval was obtained (Toetsingscommissie Wetenschappelijk Onderzoek Rotterdam en omstreken; Ikazia and Maasstad Hospital; TWOR, 2016-61). The need for informed consent was waived.

This study was performed in accordance with the Declaration of Helsinki

Consent for publication

All authors consented for publication

Availability of data and material

Available upon request

Competing interests

None

Funding

None

Authors' contributions

Laila Chomrikh Data collection, manuscript preparation

Mustafa Ahmadi Data collection, manuscript preparation

Martijn Kuijper Statistical analysis, manuscript preparation

Joris J.B. van der Vlugt Study design, manuscript preparation

Seppe J.H.A. Koopman Study design, manuscript preparation

Acknowledgements

This research did not receive any specific grant from funding agencies in the public, commercial, or notfor-profit sectors.

J Koopman received consultancy fees from Grünenthal. (€ 200). J Koopman performed research sponsored by Fresenius. ( $€ 70,000)$. These funds went to the Maasstad Hospital. And J Koopman travel expenses were paid for a site visit by medtronics (approximately $€ 100$ ). None of these were related to this study.

For the remaining authors none were declared. 


\section{References}

1 Group UER. Efficacy and safety of electroconvulsive therapy in depressive disorders: a systematic review and meta-analysis. Lancet 2003; 361: 799-808

2 Fink M. What is an adequate treatment in convulsive therapy? Acta Psychiatrica Scandinavica 1991; 84: 424-7

3 Lalla FR, Milroy T. The current status of seizure duration in the practice of electroconvulsive therapy. Can J Psychiatry 1996; 41: 299-304

4 Shapira B, Lidsky D, Gorfine M, Lerer B. Electroconvulsive therapy and resistant depression: clinical implications of seizure threshold. J Clin Psychiatry 1996; 57: 32-8

5 Benbow SM. The Practice of Electroconvulsive Therapy Recommendations for Treatment, Training and Privileging. A Task Force Report of the American Psychiatric Association, 2nd edition. American Psychiatric Association, Washington, DC, 2001. Pages: 355. International Journal of Geriatric Psychiatry 2002; 17: 1081-

6 Hooten WM, Rasmussen KG, Jr. Effects of general anesthetic agents in adults receiving electroconvulsive therapy: a systematic review. J ECT 2008; 24: 208-23

7 Kadiyala PK, Kadiyala LD. Anaesthesia for electroconvulsive therapy: An overview with an update on its role in potentiating electroconvulsive therapy. Indian J Anaesth 2017; 61: 373-80

8 Singh PM, Arora S, Borle A, Varma P, Trikha A, Goudra BG. Evaluation of Etomidate for Seizure Duration in Electroconvulsive Therapy: A Systematic Review and Meta-analysis. J ECT 2015; 31: 213-25

9 Erdoes G, Basciani RM, Eberle B. Etomidate--a review of robust evidence for its use in various clinical scenarios. Acta Anaesthesiol Scand 2014; 58: 380-9

10 Avramov MN, Husain MM, White PF. The Comparative Effects of Methohexital, Propofol, and Etomidate for Electroconvulsive Therapy. Anesthesia \& Analgesia 1995; 81: 596-602

11 Van den Broek WW, Birkenhager, T.K., de Boer, D., Burggraaf, J.P., van Gemert, B., Groenland, T.H.N., Kho, K.H., Stek, M.L., Verwey, B., van Vliet, I.M., van waarde, J.A., Wijkstra, J. Richtlijn Elektroconvulsietherapie. Nederlandse Vereniging voor Psychiatrie 2010

12 Eser D, Nothdurfter C, Schule C, et al. The influence of anaesthetic medication on safety, tolerability and clinical effectiveness of electroconvulsive therapy. World J Biol Psychiatry 2010; 11: 447-56

13 Kovac AL, Pardo M. A Comparison Between Etomidate and Methohexital for Anesthesia in ECT. Convuls Ther 1992; 8: 118-25 
14 Janouschek H, Nickl-Jockschat T, Haeck M, Gillmann B, Grozinger M. Comparison of methohexital and etomidate as anesthetic agents for electroconvulsive therapy in affective and psychotic disorders. $J$ Psychiatr Res 2013; 47: 686-93

15 Eranti SV, Mogg AJ, Pluck GC, Landau S, McLoughlin DM. Methohexitone, propofol and etomidate in electroconvulsive therapy for depression: a naturalistic comparison study. J Affect Disord 2009; 113: 16571

16 Baghai TC, Marcuse A, Brosch M, et al. The influence of concomitant antidepressant medication on safety, tolerability and clinical effectiveness of electroconvulsive therapy. World J Biol Psychiatry 2006; 7: $82-90$

17 Boccio R, Fink M. A Comparison of Etomidate and Methohexital Anesthesia for Electroconvulsive Therapy. Annals of Clinical Psychiatry 1989; 1: 39-42

\section{Figures}




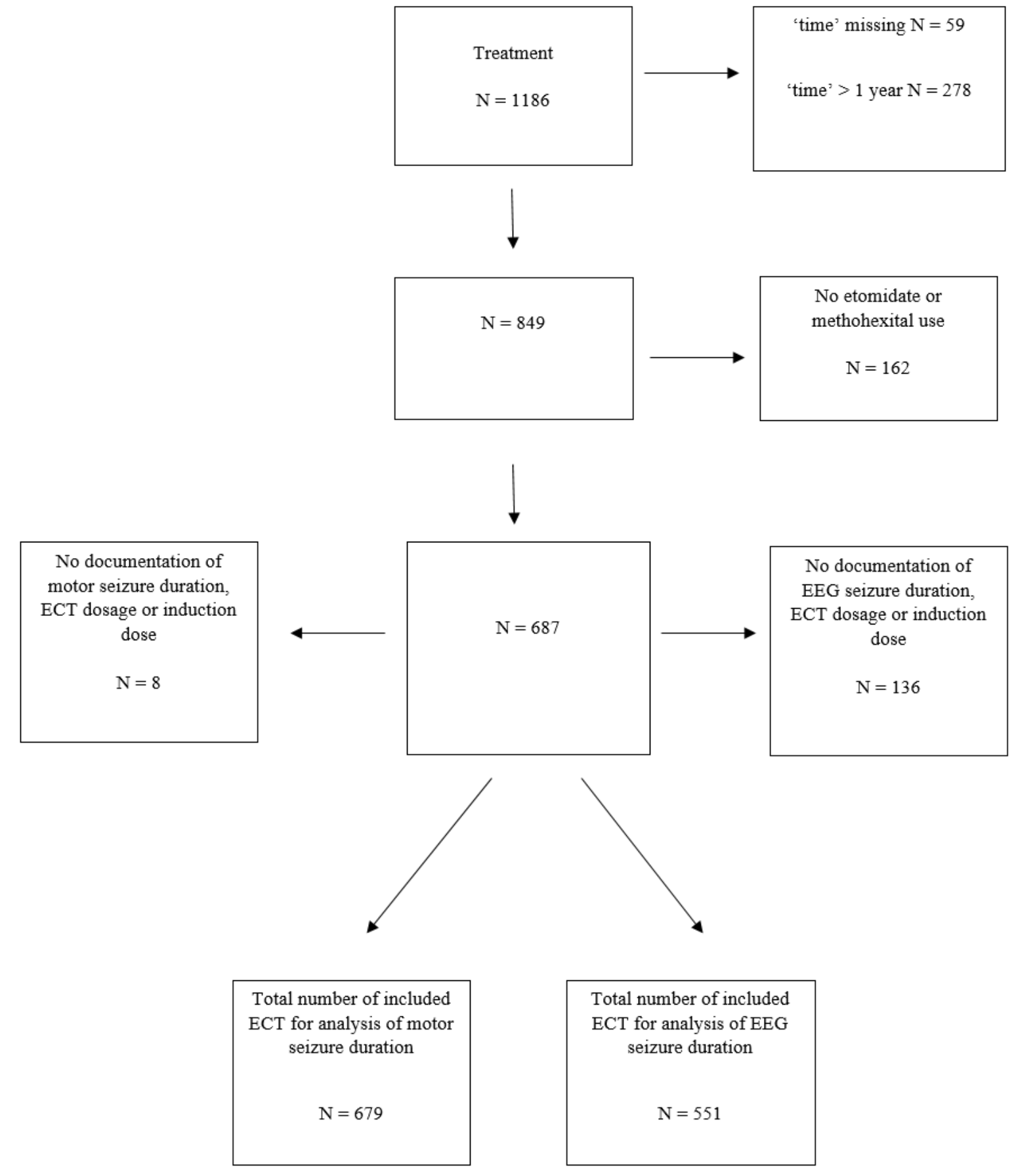

\section{Figure 1}

\section{Flowchart}

Measurements up to 365 days after start of electroconvulsive therapy were included. We excluded other anaesthetic induction agents than etomidate or methohexital. We excluded patients with missing data of motor or EEG seizure duration, ECT dosage and induction dose as well. A total number of 679 and 551 
electroconvulsive therapies were included for analysis regarding motor seizure duration and EEG seizure duration respectively.

ECT electroconvulsive therapy; EEG electroencephalography; $\mathrm{N}$ number 